\title{
BMJ Open Retrospective interrupted time series examining hypertension and diabetes medicines usage following changes in patient cost sharing in the 'Farmácia Popular' programme in Brazil
}

Isabel Cristina Martins Emmerick, ${ }^{1}$ Monica Rodrigues Campos, ${ }^{2}$ Vera Lucia Luiza, ${ }^{3}$ Luisa Arueira Chaves, ${ }^{4}$ Andrea Dâmaso Bertoldi, ${ }^{5}$ Dennis Ross-Degnan ${ }^{6}$

To cite: Emmerick ICM, Campos MR, Luiza VL, et al. Retrospective interrupted time series examining hypertension and diabetes medicines usage following changes in patient cost sharing in the 'Farmácia Popular' programme in Brazil. BMJ Open 2017;7:e017308. doi:10.1136/ bmjopen-2017-017308

- Prepublication history and additional material for this paper are available online. To view these files, please visit the journal online (http://dx. doi org/10.1136/bmjopen-2017017308)

Received 20 April 2017 Revised 29 August 2017 Accepted 30 August 2017
CrossMark

For numbered affiliations see end of article.

Correspondence to Dr Isabel Cristina

Martins Emmerick;

emmerick.isabel@gmail.com

\section{ABSTRACT}

Objectives 'Farmácia Popular' (FP) programme was launched in 2004, expanded in 2006 and changed the cost sharing for oral hypoglycaemic $(\mathrm{OH})$ and antihypertensive (AH) medicines in 2009 and in 2011. This paper describes patterns of usage and continuity of coverage for $\mathrm{OH}$ and $\mathrm{AH}$ medicines following changes in patient cost sharing in the FP.

Study design Interrupted time series study using retrospective administrative data.

Methods Monthly programme participation (PP) and proportion of days covered (PDC) were the two outcome measures. The open cohort included all patients with two or more dispensings for a given study medicine in 2008-2012. The interventions were an increase in patient cost sharing in 2009 and zero patient cost sharing for key medicines in 2011.

Results A total of 3.6 and 9.5 million patients receiving treatment for diabetes and hypertension, respectively, qualified for the study. Before the interventions, PP was growing by $7.3 \%$ per month; median PDC varied by medicine from $50 \%$ to $75 \%$. After patient cost sharing increased in 2009, PP reduced by $56.5 \%$ and PDC decreased for most medicines (median 60.3\%). After the 2011 free medicine programme, PP surged by 121000 new dispensings per month and PDC increased for all covered medicines (80.7\%).

Conclusion Cost sharing was found to be a barrier to continuity of treatment in Brazil's private sector FP programme. Making essential medicines free to patients appear to increase participation and continuity of treatment to clinically beneficial levels (PDC >80\%).

\section{BACKGROUND}

Brazil has three main mechanisms by which individuals obtain access to medicines: out-of-pocket purchase in private pharmacies, provision in public health facilities and the 'Farmácia Popular' (FP) programme. For out-of-pocket purchase, there are about 63000 private pharmaceutical outlets all over the country, although the wealthier Southeast

\section{Strengths and limitations of this study}

- This paper contributes to our understanding of the impacts of sequential national policies in Brazil's Farmácia Popular (FP) programme that were intended to improve access to medicines for noncommunicable diseases in a middle-income country.

- Reduced programme participation when patient cost sharing was increased and dramatic increases when key essential medicines were dispensed free of charge in private sector pharmacies provide important evidence about the impact of financial barriers on strategies to improve adherence to use of chronic medicines.

- The analysis uses the strongest quasi-experimental design-interrupted times series with segmented regression analysis - to evaluate policy impacts.

- The study is limited to patients treated under the FP programme and not the entire population in Brazil. Overlaps between the FP programme and other medicines provision mechanisms in the country including public sector health facilities could not be analysed.

- The analyses of medicine usage are based on dispensed amounts and enable us to evaluate average availability over time, but not actual adherence to treatment, overuse of medicines or potential diversion outside of the programme.

region was responsible for $51.9 \%$ of sales in 2013. ${ }^{1}$ Medicines have been offered free-ofcharge in all levels of public healthcare facilities since the 1970s. ${ }^{2}$ The National Essential Medicines List, comprising 840 items in 2014, is the reference list for public coverage. ${ }^{3}$

FP, a new medicines subsidy programme created in 2004, ${ }^{4}$ has evolved in four phases. In the first phase, FP was implemented only in government-owned pharmacies to address persistent shortages of medicines in public health facilities. Medicines were 
sold at cost price plus operating cost, with selling prices $64 \%-90 \%$ lower than the private market. ${ }^{5}$ In the second phase, beginning in 2006 ('Aqui tem Farmácia Popular', AFP-I), a limited list of essential medicines (see complete list in each phase in ref. 4) was authorised to be sold in private pharmacies contracted by the Ministry of Health. The government paid either $90 \%$ of a government-established reference price for each medicine or $90 \%$ of the selling price, whichever was less; patients paid the remaining value not covered by the government. In the third phase, beginning in 2009 (AFP-II), administrative changes were introduced to improve accountability and reference prices were reduced for most medicines, resulting in increases in the patient's share. ${ }^{4}$ In the fourth phase, beginning in February 2011 ('Saúde Não Tem Preço', SNP), oral hypoglycaemic (OH) and antihypertensive $(\mathrm{AH})$ medicines that were already in the programme list began to be offered free-of-charge to patients in both government-owned and contracted private pharmacies, with the government paying a fixed negotiated price per medicine. In 2014, FP accounted for about 2.4billion 'reais' (US $\$ 1.09$ billion) in government expenditures. ${ }^{6}$

$\mathrm{OH}$ and $\mathrm{AH}$ medicines present in the programme's list were covered in all phases of FP programme as part of broad ranging government initiatives to address these two non-communicable diseases. ${ }^{7}$ One measure of private sector FP's contribution to control of these two illnesses is the proportion of days covered (PDC) by medicines dispensed by private FP pharmacies. PDC is a commonly used refill-based measure of treatment adherence $^{8-12}$; in this study, it refers to consistency of dispensing from the FP programme, as there are other unobserved sources of medicines available to patients.

This paper aims to analyse changes in programme participation and PDC for $\mathrm{OH}$ and $\mathrm{AH}$ medicines covered in the FP following changes in cost sharing during the AFP-II and SNP phases of the private sector FP programme, using AFP data from January 2008 through December 2012. Comparable patient-level data are not available to evaluate changes in usage of the public sector FP programme.

\section{METHODS \\ Design}

This study is a retrospective, quantitative, analytic study using interrupted time series based on administrative data and using an open cohort.

\section{Intervention}

The study interventions are two changes in patient cost sharing in AFP. In April 2009, the government reduced reference prices for most FP medicines by an average of $24.5 \%$, resulting in an immediate increase in patient copayment from an average of 2.45 'reais' to 3.88 'reais' per 30 days dispensing, a relative increase of $58.4 \%$ (for complete information on prices for each medicine, see onlinesupplementary appendix 1). In February 2011, the government made all covered medicines for hypertension and diabetes free to patients, reimbursing pharmacies according to a set of negotiated prices.

\section{Data source and study population}

There have been no changes in FP eligibility criteria during the programme. To have a medicine dispensed at any FP private pharmacy, a patient must present a valid prescription and a national ID. Medicines were dispensed on a monthly basis, although prescriptions were valid for 120 days. Over time, the number of participating private sector pharmacies has expanded substantially, especially in some regions. ${ }^{4}$

Data are derived from an electronic point-of-sales dispensing programme implemented in 2006 in FP retail pharmacies. Available data include patient and pharmacy identifiers, patient age and gender, facilities geographic location, date of dispensing, name and quantity of medicine dispensed, daily prescribed dose, Ministry of Health reimbursement and patient copayment. For this paper we use data on dispensings of hypertension and diabetes medicines from January 2008 to December 2012. Dispensing data are of good quality and relatively complete, with duplicate cases accounting for $<0.005 \%$ and individual-level missing data at $<0.05 \%$. We excluded encounters with missing data from all analyses.

Patients are included only if they received two or more dispensings for a given medicine during the study period. We used an open cohort, which means that when a patient had a dispensing he enter the analysis and was kept in it for 120 days (maximum time that the prescription is valid in Brazil). If the patient did not have a 'new dispensing' during the 120 days interval, the patient fall out of the analysis and it is not in the denominator any more. Patients with a single dispensing were considered occasional buyers and, for that reason were excluded from the analysis.

\section{Analysis}

The primary outcome variables were the number of monthly dispensings of AFP programme medicines and the monthly median PDC for included patients. All dispensings were for a 30-day supply. Medicines covered by the programme include four to treat diabetes (glibenclamide $5 \mathrm{mg}$, and metformin $500 \mathrm{mg}, 850 \mathrm{mg}$ and slow release $500 \mathrm{mg}$ ) and six for hypertension (atenolol $25 \mathrm{mg}$, propranolol $40 \mathrm{mg}$, hydrochlorothiazide $25 \mathrm{mg}$, captopril $25 \mathrm{mg}$, enalapril $5 \mathrm{mg}$ and losartan $50 \mathrm{mg}$ ). The number of days covered by a dispensing was defined as the amount of medicines dispensed divided by the prescribed daily dose. Days of therapy remaining in hand from prior dispensings were used to extend the number of days covered; possible overuse due to overlapping dispensings was not evaluated. ${ }^{12}$

We calculated monthly PDC as the number of days of therapy available during a month divided by the number of days in the month, with PDC thus varying between $0 \%$ and $100 \%^{12}$; the calculation for the first month 
of treatment considered only the days after the first dispensing. The median, 25th and 75th percentile PDCs represent aggregate values across all patients who were in an episode of treatment with that medicine during the month.

\section{Statistical methods}

We used interrupted time series (ITS) segmented linear regression models to determine the effect of the FP policy changes on the two study outcomes. In estimating effects, ITS models adjust for pre-existing trends in the period before the policy change. Segmented linear regression models were constructed using the prais command in STATA V.12.

ITS models included three segments, one per programme period, with 15, 22 and 23 monthly observations, respectively. The baseline segment was fit with an intercept and a variable estimating trend. We estimate each policy effect by one variable representing the change in level of the outcome immediately after the policy and a second representing the change in trend of the postpolicy segment. Patients experienced the changes in cost sharing only when they presented to fill a prescription after the policy change. We thus defined a postpolicy implementation period of 2 months for participation and 6 months for PDC (to account for the 120 day refill period); these periods were excluded in the ITS models so that we could estimate stable postintervention effects.

We retained all parameters in the models regardless of statistical significance. We highlight the results with $\mathrm{p}<0.05$. We also tested logarithmic trend terms to accommodate possible non-linear trends during each postintervention segment, selecting the best model using the $\mathrm{BIC}$ and AIC goodness of fitness criteria. ${ }^{13}$ For the trends in metformin $500 \mathrm{mg}$, atenolol $25 \mathrm{mg}$ and enalapril $5 \mathrm{mg}$ dispensing after the 2009 increase in cost sharing, the natural $\log$ of trend represented a better model fit. We tested the adequacy of each model by residual analysis. To create single number summaries of policy effects, we calculated estimates of the relative changes in outcomes compared with expected values based on prior trends in April 2010 and February 2012, about 1 year after the two cost-sharing interventions.

\section{RESULTS}

A total of 6032380 and 14392076 patients who received any $\mathrm{OH}$ or $\mathrm{AH}$, respectively, from the $\mathrm{FP}$ programme comprised the dataset; of these, 3611512 (59.9\%) and $9534333(66.25 \%)$ patients received two or more dispensings (table 1). The mean age was 57 years for both diabetes and hypertension patients, with females

Table 1 Patients participating in Brazil's 'FP is available here' programme, total and with two or more dispensings versus one dispensing, by gender, age and region, 2008-2012

\begin{tabular}{|c|c|c|c|c|c|c|c|}
\hline & & \multicolumn{2}{|l|}{ Total } & \multicolumn{2}{|c|}{$\begin{array}{l}\text { Two or more } \\
\text { dispensings }\end{array}$} & \multicolumn{2}{|c|}{ One dispensing only } \\
\hline \multicolumn{8}{|l|}{ Diabetes } \\
\hline \multirow[t]{2}{*}{ Gender (n, \%) } & Woman & 3602944 & $59.7 \%$ & 2168131 & $60.0 \%$ & 1434813 & $59.3 \%$ \\
\hline & Man & 2413718 & $40.0 \%$ & 1433895 & $39.7 \%$ & 979823 & $40.5 \%$ \\
\hline \multirow{3}{*}{ Region (n, \%) } & Southeast & 3769151 & $62.5 \%$ & 2336807 & $64.7 \%$ & 1432344 & $59.2 \%$ \\
\hline & South & 885391 & $14.7 \%$ & 540572 & $15.0 \%$ & 344819 & $14.2 \%$ \\
\hline & West-Centre & 359324 & $6.0 \%$ & 209963 & $5.8 \%$ & 149361 & $6.2 \%$ \\
\hline Total & & 6032380 & $100.0 \%$ & 3611512 & $100.0 \%$ & 2420868 & $100.0 \%$ \\
\hline Gender (n, \%) & Man & 5714487 & $39.7 \%$ & 3728721 & $39.1 \%$ & 1985766 & $40.9 \%$ \\
\hline \multirow[t]{5}{*}{ Region (n, \%) } & North & 469739 & $3.3 \%$ & 232250 & $2.4 \%$ & 237489 & $4.9 \%$ \\
\hline & Northeast & 2121308 & $14.7 \%$ & 1201133 & $12.6 \%$ & 920175 & $18.9 \%$ \\
\hline & Southeast & 8290832 & $57.6 \%$ & 5714243 & $59.9 \%$ & 2576589 & $53.0 \%$ \\
\hline & South & 2562095 & $17.8 \%$ & 1780678 & $18.7 \%$ & 781417 & $16.1 \%$ \\
\hline & West-Centre & 948102 & $6.6 \%$ & 606029 & $6.4 \%$ & 342073 & $7.0 \%$ \\
\hline Total & & 14392076 & $100.0 \%$ & 9534333 & $100.0 \%$ & 4857743 & $100.0 \%$ \\
\hline
\end{tabular}

FP, Farmácia Popular. 


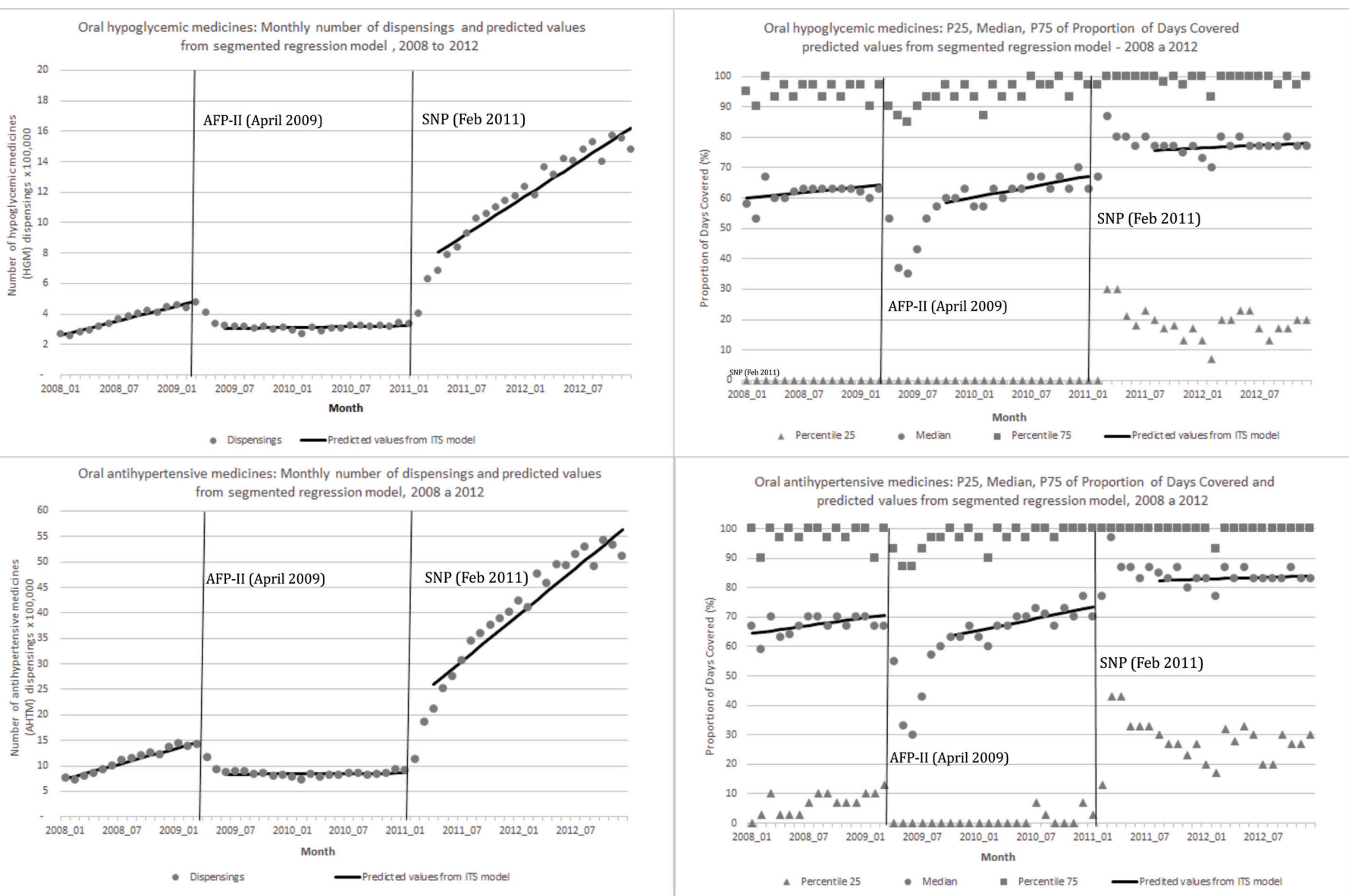

Figure 1 Number of dispensings and 25th/median/75th percentiles of PDC, and predicted values from segmented regression models for oral HGM and oral AHTM, by stage of the FP programme, Brazil, 2008-2012. AFP-II, Aqui tem Farmácia Popular II; AHTM, antihypertensive medicines; FP, Farmácia Popular; ITS, interrupted times series; HGM, hypoglycaemic medicines; PDC, proportion of days covered; SNP, Saúde Não Tem Preço.

comprising about $60 \%$ of patients; the Southeast region represented the majority of patients in the programme. Patients with two or more dispensings did not differ significantly from those with a single medication fill in age, gender or region.

During the baseline period prior to the cost-sharing changes, patients filled an average of 1.1 and 2.7 million dispensings per medicine per year for diabetes mellitus and hypertension, respectively; dispensings were growing at an average rate of $7.4 \%$ per month for the medicines analysed (figure 1, table 2). Metformin $850 \mathrm{mg}$ was the most widely used $\mathrm{OH}$ medicine and had the highest rate of growth, while metformin slow release had the smallest monthly number of dispensings (see onlinesupplementary appendix 2); enalapril was the most widely used AH medicine and propranolol the least widely used, but usage of all $\mathrm{AH}$ medicines was growing rapidly (see online supplementary appendix 3 ).

Prior to the increased cost sharing, PDC levels for studied medicines were relatively stable; by March 2009, 1 month before the AFP-II policy, median PDC levels for $\mathrm{OH}$ and $\mathrm{AH}$ medicines were $64.2 \%$ and $70.4 \%$, respectively. Median PDC levels varied across covered medicines from $63.3 \%$ (metformin slow release) to $78.7 \%$ (captopril
$25 \mathrm{mg}$ ) (figure 1 , table 3 , supplementary appendix 2 and 3.

\section{Cost-sharing increases (AFP-II)—April 2009}

After patient copayments increased, $\mathrm{OH}$ dispensings declined immediately by -2.12 per $100000 \quad(95 \%$ CI -3.13 to -1.10 ) compared with 4.85 per 100000 in March 2009, immediately before the policy (table 2). In addition, the previous upward monthly trend in participation flattened to nearly zero (slope change -0.15 per month, $(-0.24$ to -0.06$))$. By 1 year after the policy, dispensings had declined by $54.5 \%$ ( $-65.9 \%$ to $-43.0 \%)$ compared with where they would have been had baseline trends continued. Similarly, dispensings of AH medicines declined by -7.8 per $100000(-12.1$ to -2.45$)$ from their level of 14.6 per 100000 immediately before the AFP-II policy. As with $\mathrm{OH}$ medicines, the previous monthly increase in participation of 0.51 declined by -0.5 (-0.93 to -0.06$)$. After 1 year, participation was $60.1 \%$ (-76.1 to -44.2$)$ lower than expected based on prior trends (table 2).

After AFP-II, rates of monthly dispensing for most studied medicines followed similar patterns. Dispensing had been increasing by 1600 (metformin $500 \mathrm{mg}$ ) to 


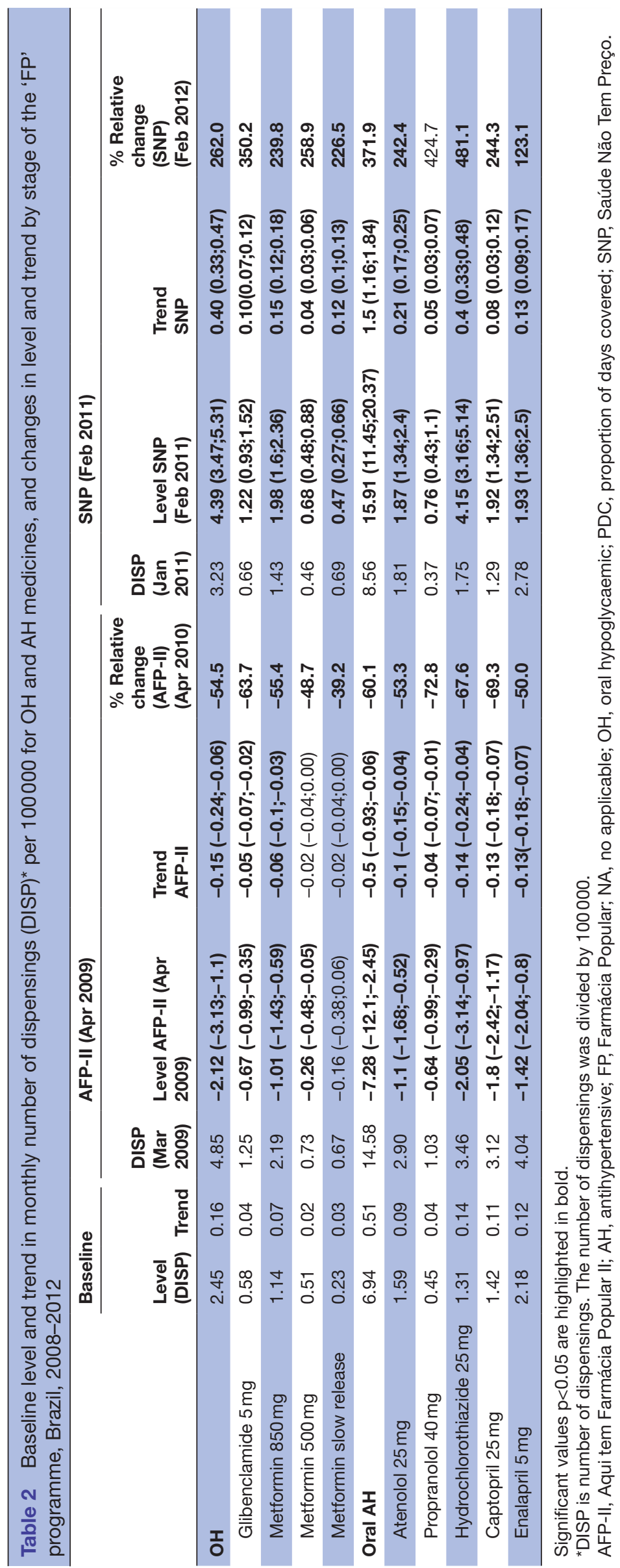




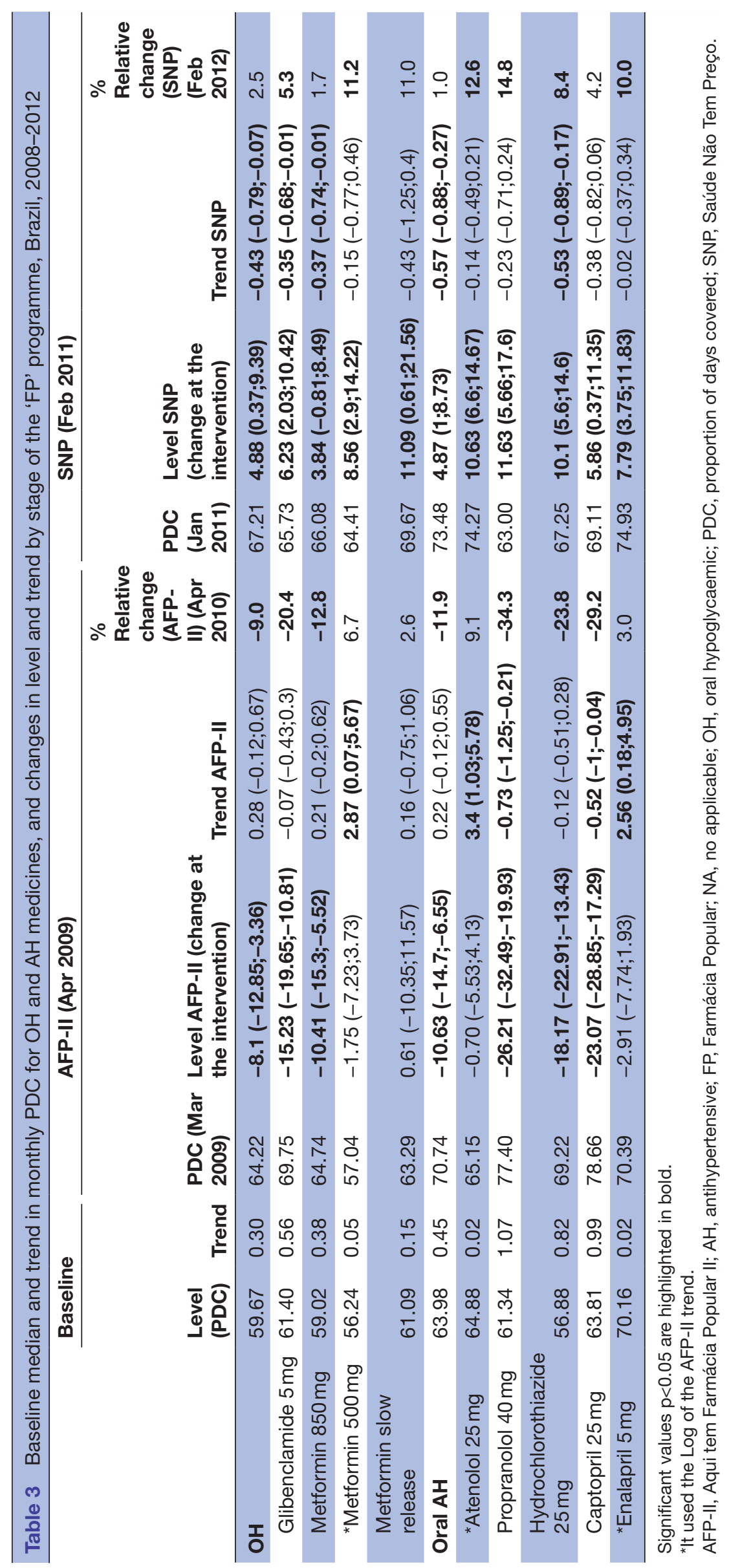


14000 (hydrochlorothiazide $25 \mathrm{mg}$ ) fills per month prior to the increased cost sharing. After AFP-II implementation, there were immediate reductions in participation and flattened rates of dispensing that persisted over time. By 1 year after the intervention, in April 2010, all medicines had experienced significant relative decreases varying from $39.2 \%$ for metformin slow release to $72.8 \%$ for propranolol $40 \mathrm{mg}$ (table 2).

After patient copayments increased and substantial numbers of patients left the programme, median PDC declined for $\mathrm{OH}$ medicines by $8.11 \%(-12.85 \%$ to $-3.36 \%)$ and for AH medicines by $10.61 \%(-14.7 \%$ to $-6.55 \%$ ). While the AFP policy remained in effect (until December 2010), median monthly PDC tended to increase slightly among participating patients $(\mathrm{OH}$ medicines: 0.28 per month (-0.12 to 0.67$)$; AH medicines: 0.22 $(-12$ to 0.55$))$. By 1 year after the policy, median PDC had declined for $\mathrm{OH}$ medicines by $9.0 \%(-18.0 \%$ to $-5.8 \%)$ and for AH medicines by $11.9 \%$ (-26.3 to -14.4$)$ relative to where they would have been had baseline trends continued (table 3 ).

Changes in PDC following increased cost sharing varied across medicines. PDC for five of the nine medicines covered decreased by $12.8 \%$ (metformin $850 \mathrm{mg}$ ) to $34.3 \%$ (propranolol $40 \mathrm{mg}$ ). However, four medicines actually experienced small non-significant increases in PDC for patients remaining in the programme by a year after the cost sharing increase (table 3 ).

\section{Availability of free medicines (SNP)—February 2011}

After the SNP implementation, dispensings of $\mathrm{OH}$ medicines increased by 4.39 per 100000 (3.47 to -5.31 ) compared with 3.23 per 100000 in January 2011, immediately before the policy (table 2). Additionally, there was an upward monthly trend in dispensings of 0.40 per month $(0.33$ to, 0.47$)$ contrasting with the previous flattened trend. By a year after the policy, dispensings had increased by $262 \%$ (130.7 to 393.3) compared with where they would have been had previous trends continued. AH medicines followed the same pattern; dispensings increased by 15.9 per 100000 (11.45 to 20.37) from their level of 8.6 per 100000 immediately before the SNP policy. Participation increased by 1.5 (1.16 to 1.84) per 100000 per month. After 1 year, participation was $372 \%$ (57.2 to 686.6) higher than expected based on prior trend (table 2).

After SNP, rates of monthly dispensing for most medicines followed similar patterns, varying from an immediate increase in participation of 47000 (metformin slow release) to 415000 (hydrochlorothiazide $25 \mathrm{mg}$ ) fills per month; increases in trend of monthly dispensing persisted over time. By 1 year after the free medicines policy, in February 2012, significant relative increases varied from $226 \%$ to $481 \%$ for metformin slow release and hydrochlorothiazide $25 \mathrm{mg}$, respectively (table 2 ).

Losartan was added to the medicines reference list in October 2010; by the time of SNP implementation 4 months later, there were only about 10000 dispensings.
By 1 year after medicines became free to patients, losartan dispensings had increased to $>2$ million dispensings. In comparison, its therapeutic competitors captopril and enalapril had only 700000 and 1 million dispensings, respectively, in February 2012 (see online supplementary appendix 2).

After SNP and the substantial influx of patients, median monthly PDC increased for $\mathrm{OH}$ medicines by $4.88 \%(0.37 \%$ to $9.39 \%)$ and for AH medicines by $4.87 \%$ $(1.00 \%$ to $8.73 \%)$, and remained relatively constant until the end of the study period (December 2012) (table 3). Changes in PDC varied by medicine; six of the nine medicines covered increased significantly by $5.3 \%$ (glibenclamide $5 \mathrm{mg}$ ) to $14.8 \%$ (propranolol $40 \mathrm{mg}$ ), but three experienced only small, non-significant increases by the year after the free medicine policy (table 3 ).

\section{DISCUSSION}

Coverage policies in 'FP', a publicly financed programme designed to increase access to essential medicines in Brazil, have evolved over time. Patient cost sharing increased by $58 \%$ in 2009 , resulting in immediate decreases in programme participation and PDC. In contrast, rapid increases in both outcomes followed implementation of a 2011 policy to make essential medicines for diabetes and hypertension free to patients.

Programme participation for hypertension and diabetes follow the prevalence profile of these two diseases in the country. ${ }^{14}$ The majority of AFP patients are from the wealthier Southeast region where there is a higher density of participating pharmacies ${ }^{4}$; this may imply increasing socioeconomic disparities in access to treatment for diabetes and hypertension, especially now that medicines are available for free. Other studies that have evaluated access to medicines for hypertension ${ }^{15}$ and diabetes ${ }^{16}$ through the Health has No Price programme have concluded that the intervention contributed to increased access to these medicines in Brazil.

The impact of cost-sharing interventions on the use of medicines has been addressed in the literature. ${ }^{17}$ It may be expressed in terms of the amount used, measured as sales volume or prescriptions filled, of expenditures or sales, healthcare usage or health outcomes.

PDC is usually used in the literature as a proxy for treatment adherence. ${ }^{91218}$ Therefore, it is a measure of use of medicines with a closer link to health outcomes. In this paper, PDC measures consistency of filling in the AFP programme. Since prescriptions can be filled in either public or private FP pharmacies, available data are insufficient to determine the actual level of prescription filling in the programme; the observed PDC can be thought of as measuring a minimum level of programme adherence.

In the literature, about half of patients treated for chronic disease become no adherent within a year. ${ }^{19}$ The consistency of prescription filling in the AFP programme, particularly after medicines for diabetes and hypertension were made free to patients, suggest that private 
sector outlets are convenient and preferred by patients as a source of these free medicines.

The relationship between PDC levels and clinical outcomes is well-established in the literature. ${ }^{20}{ }^{21}$ For example,adherence tohypoglycaemic treatmentmeasured through administrative data has been found to be related to better glycaemic control, fewer emergency department visits and lower rates of hospital admission. ${ }^{22-24}$ Many studies consider patients with PDC $80 \%$ or higher to be adherent to treatment ${ }^{22}$; lower adherence can lead to higher rates of adverse events, poor long-term health outcomes and higher healthcare costs. ${ }^{25}$ After SNP, rates of PDC were higher than $80 \%$ for well over half of patients taking $\mathrm{OH}$ and $\mathrm{AH}$ medicines, levels likely to have positive impact on clinical outcomes. One study that analysed the impact of full subsidy policies on medicines use have found similar effects on PDC as in our study. ${ }^{11}$ 26-29

The relationship between cost sharing and medication adherence has been widely studied. ${ }^{17}$ In our study, all medicines with increased copayments in April 2009 experienced decreases in rates of dispensing and PDC. After SNP, we observed the opposite response; when patients had no cost sharing, programme participation and PDC increased dramatically.

Although losartan is not a first-line treatment in the Brazilian guideline to treat hypertension, ${ }^{29}$ it was included in the FP reimbursement list in 2010. Within a few months, losartan had become the most widely dispensed AH medicine. Coverage decisions in government subsidy programme should be consistent with treatment guidelines to encourage appropriate choice of therapy and more cost-effective treatment.

The limitations of this study comprises that the patientlevel usage data are only available from private AFP pharmacies and not from government-owned pharmacies. Thus, this study does not evaluate the impact of these two cost-sharing interventions on usage in the FP programme as a whole or on the actual PDC for patients who filled prescriptions in both sectors. Nevertheless, the public arm accounts for about 2.2\% of FP dispensing facilities. ${ }^{4}$ We have the issue that there are other sources for medicines to patients. However, we did not intend to use PDC as adherence to treatment measure, but as adherence to the programme instead. The dispensings in FP programme are monthly, for 30 days' supply, so no stockpiling is possible due the programme rules. Then, we think that these potential treats to internal validity have negligible impact on our findings. To make the estimates of PDC interpretable, we limited analysis of programme impacts to patients who filled more than one prescription of a medicine in the FP private sector; there were no relevant differences in characteristics between patients who filled only one prescription and those who used it more regularly. We have no data on medicines that are not part of the programme, so cannot evaluate the impact of FP programme policies on use of other medicines used to treat diabetes and hypertension. As patients could have switched treatment among the medicines covered (eg, change from captopril to enalapril), we may have underestimated PDC because we did not evaluate this possible change. That way, the median PDC would be lower when actually the patient was changing the therapy and using other medicine. Finally, as a result of the method chosen to calculate the PDC, ${ }^{12}$ the possible overuse due to overlapping dispensings was not evaluated.

In conclusion, participation in the ' $\mathrm{FP}$ ' private sector programme evolved in response to two cost-sharing interventions implemented between 2008 and 2012. Increased patient cost sharing reduced participation, while full subsidy of key medicines in private pharmacies substantially increased participation; patients in the programme achieved PDC levels that have been shown to improve health outcomes. Risks to rational use of medicines, especially overuse, can be minimised through controlling mechanisms, such as the requirement of prescription, validity of prescriptions and maximum dispensing amounts. Policy-makers should consider reducing or removing cost sharing for essential medicines to treat chronic illness, while aligning subsidies to encourage greater use of first-line therapies.

\section{Author affiliations}

${ }^{1}$ Department of Population Medicine, Harvard Medical School \& Harvard Pilgrim Health Care Institute, Boston, Massachusetts, USA

${ }^{2}$ Department of Social Sciences, Sergio Arouca National School of Public Health, Oswaldo Cruz Foundation, Rio de Janeiro, Brazil

${ }^{3}$ Department of Medicines Policy and Pharmaceutical Services, Sergio Arouca National School of Public Health, Oswaldo Cruz Foundation, Rio de Janeiro, Brazil ${ }^{4}$ Department of Pharmacy, Federal University of Rio de Janeiro, Macaé, Brazil ${ }^{5}$ Postgraduate Program in Epidemiology, Federal University of Pelotas, Pelotas, Brazil

${ }^{6}$ Department of Population Medicine, Harvard Medical School and Harvard Pilgrim Health Care Institute, Boston, Massachusetts, USA

Acknowledgements The authors thank the Ministry of Health in Brazil for providing the data used in this study. IE was supported by CNPQ process number 202246/2012-4 and the Pyle Fellowship of Harvard Pilgrim Health Care Institute.

Contributors All authors made substantial contribution to study conception, ICME MRC and DRD: made substantial contribution to study design. ICME, VLL, MRC, LAC and ADB: were responsible for data acquisition. ICME, MRC and DRD: were responsible for data analysis. ICME: drafted the article and is guarantor. All authors: made substantial contribution to study conception; contributed to interpretation of data; provided critical revisions for important intellectual content and approved the final version.

Funding Research grant from the World Health Organization Alliance for Health Policy and Systems Research. IE is supported by the Pyle Fellowship of Harvard Pilgrim Health Care Institute. DRD is supported in part by the Health Delivery Systems Center for Diabetes Translational Research (HDS-CDTR) (NIDDK grant 1P30-DK092924).

Competing interests IE, principal investigator, reports grants from World Health Organization Access to Medicines Research Network, during the conduct of the study. MRC, VLL, LAC, ADB and DRD report personal fees from WHO Access to Medicines Research Network, during the conduct of the study; VLL also reports personal fees from 0swaldo Cruz Foundation (Fiocruz), outside the submitted work.

Ethics approval The Brazilian National Ethics Committee, by the National School of Public Health-Fiocruz-Brazil and the WHO ERC, approved the ISAUM-Br project, which is the base for this paper. This work was conducted in collaboration among the following institutions: Department of Medicines Policy and Pharmaceutical Services, Sergio Arouca, National School of Public Health, Fiocruz Brazil; Department of Epidemiology, University of Pelotas, Brazil; Department of Pharmaceutical Services/Office of Science Technology and Strategic 
Resources-Ministry of Health and the Department of Population Medicine, Harvard Medical School and Harvard Pilgrim Health Care Institute.

Provenance and peer review Not commissioned; externally peer reviewed.

Data sharing statement The authors do not have ownership of the data, all were acquired specifically to be used in ISAUM-Br project and there are no data that can be shared.

Open Access This is an Open Access article distributed in accordance with the Creative Commons Attribution Non Commercial (CC BY-NC 4.0) license, which permits others to distribute, remix, adapt, build upon this work non-commercially, and license their derivative works on different terms, provided the original work is properly cited and the use is non-commercial. See: http://creativecommons.org/ licenses/by-nc/4.0/

(C) Article author(s) (or their employer(s) unless otherwise stated in the text of the article) 2017. All rights reserved. No commercial use is permitted unless otherwise expressly granted.

\section{REFERENCES}

1. Econômico V. Valor: Análise setorial: Farmácias e Drogarias, 2014.

2. Bermudez JAZ, Oliveira MA, Luiza VL, et al. Políticas e Sistema de Saúde no Brasil. In: Giovanella L, Escorel S, Lenaura de Vasconcelos Costa Lobato, eds. Assistência Farmacêutica. Fiocruz: Rio de Janeiro, 2012:761-94.

3. Brasil. Ministério da Saúde. Secretaria de Ciência, Tecnologia e Insumos Estratégicos. Relação Nacional de Medicamentos Essenciais: RENAME 2014. 9th ed. Brasília: Ministério da Saúde, 2014.

4 Emmerick IC, do Nascimento JM, Pereira MA, et al. Farmácia popular program: changes in geographic accessibility of medicines during ten years of a medicine subsidy policy in Brazil. $J$ Pharm Policy Pract 2015;8.

5 Santos-Pinto CDB, Miranda ES, Martins Emmerick IC, et al. Medicine prices and availability in the Brazilian popular pharmacy program [Preços e disponibilidade de medicamentos no Programa Farmácia Popular do Brasil]. Rev Saude Publica 2010;44:611-9.

6 . Brasil. Ministério da Saúde. Plano de ações estratégicas para o enfrentamento das doenças crônicasnão transmissíveis (DCNT) no Brasil 2011-2022, 2015. http://sage.saude.gov.br/ (accessed 29 Sep 2015)

7. Brasil. Ministério da Saúde. Secretaria de Vigilância em Saúde. Departamento de Análise deSituação de Saúde. Plano de ações estratégicas para o enfrentamento das doenças crônicas não transmissíveis (DCNT). Brasília: Ministério da Saúde, 2011.

8 Sattler EL, Lee JS, Perri M. Medication (re)fill adherence measures derived from pharmacy claims data in older Americans: a review of the literature. Drugs Aging 2013;30:383-99.

9 Andrade SE, Kahler KH, Frech F, et al. Methods for evaluation of medication adherence and persistence using automated databases. Pharmacoepidemiol Drug Saf 2006;15:565-74.

10 An J, Nichol MB. Multiple medication adherence and its effect on clinical outcomes among patients with comorbid type 2 diabetes and hypertension. Med Care 2013;51:879-87.

11. Athanasakis K, Skroumpelos AG, Tsiantou V, et al. Abolishing coinsurance for oral antihyperglycemic agents: effects on social insurance budgets. 2011;17:130-5.
12 Hess LM, Raebel MA, Conner DA, et al. Measurement of adherence in pharmacy administrative databases: a proposal for standard definitions and preferred measures. Ann Pharmacother 2006:40:1280-8.

13. Maydeu-Olivares A. Goodness-of-fit testing. http://www.ub.edu/ gdne/amaydeusp_archivos/encyclopedia_of_education10.pdf (accessed 10 Feb 2016)

14. Brasil. Ministério da Saúde. Vigitel Brasil 2013: vigilânciade fatores de risco e proteção para doenças crônicas. Brasília: Ministério da Saúde, 2014.

15 Araujo JL, Pereira MD, de Sá Del Fiol F, et al. Access to antihypertensive agents in Brazil: evaluation of the "health has no price" program. Clin Ther 2014;36:1191-5.

16 Araujo JL, Pereira MD, de Cássia Bergamaschi C, et al. Access to medicines for diabetes treatment in Brazil: evaluation of "health has no price" program. Diabetol Metab Syndr 2016;8.

17 Luiza VL, Chaves LA, Silva RM, et al. Pharmaceutical policies: effects of cap and co-payment on rational use of medicines. Cochrane Database of Systematic Reviews: John Wiley \& Sons, Ltd, 2015. http://onlinelibrary.wiley.com/doi/ (accessed 12 May 2015).

18 Steiner JF, Prochazka AV. The assessment of refill compliance using pharmacy records: methods, validity, and applications. J Clin Epidemiol 1997;50:105-16.

19 Franklin JM, Krumme AA, Shrank WH, et al. Predicting adherence trajectory using initial patterns of medication filling. Am J Manag Care 2015;21:e537 http://www.ajmc.com/journals/issue/2015/ $2015 \mathrm{vol} 21 \mathrm{ng} /$.

20 Elhayany A, Vinker S. Addressing healthcare inequities in Israel by eliminating prescription drug copayments. Am J Manag Care 2011;17:e255-9.

21 Lynch WD, Markosyan K, Melkonian AK, et al. Effect of antihypertensive medication adherence among employees with hypertension. Am J Manag Care 2009;15:871-80.

22 Nair KV, Miller K, Saseen J, et al. Prescription copay reduction program for diabetic employees: Impact on medication compliance and healthcare costs and utilization. , 2009:2, 14-24.

23 Asche C, LaFleur J, Conner C. A review of diabetes treatment adherence and the association with clinical and economic outcomes. Clin Ther 2011;33:74-109.

24 Nichols GA, Rosales AG, Kimes TM, et al. Impact on glycated haemoglobin of a biological response-based measure of medication adherence. Diabetes Obes Metab 2015;17:843-8 http://onlinelibrary. wiley.com/doi/.

25 Roebuck MC, Liberman JN, Gemmill-Toyama M, et al. Medication adherence leads to lower health care use and costs despite increased drug spending. Health Aff 2011;30:91-9.

26 Huber CA, Rapold R, Brüngger B, et al. One-year adherence to oral antihyperglycemic medication and risk prediction of patient outcomes for adults with diabetes mellitus: An observational study. Medicine 2016;95:e3994.

27 Cramer JA. A systematic review of adherence with medications for diabetes. Diabetes Care 2004;27:1218-24.

28 Ho PM, Rumsfeld JS, Masoudi FA, et al. Effect of medication nonadherence on hospitalization and mortality among patients with diabetes mellitus. Arch Intern Med 2006;166:1836-41.

29 Saúde M. Secretaria de Atencão à SaúdeDepartamento de Atenção Básica. Estratégias para o cuidado da pessoa com doença crônica: hipertensão arterial sistêmica [Strategies for the care of the person with chronic disease: systemic arterial hypertension. 1st Edition: Ministerio da Saúde, Brazil Brazil, 2013. http://bvsms.saude.gov.br/ bvs/publicacoes/estrategias_cuidado_pessoa_doenca_cronica.pdf. 